\title{
Common Anomalies Associated To Congenital Vertical Talus: A Single Center Experience
}

\author{
Elmas Muhsin* \\ Department of Medical Genetic, Afyon Kocatepe University, Turkey
}

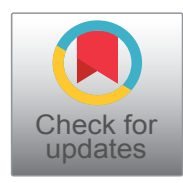

*Corresponding author: Elmas Muhsin, Department of Medical Genetic, Afyon Kocatepe University, Afyonkarahisar, Turkey

\begin{abstract}
Background: Congenital vertical talus is defined as a foot deformity in which the calcaneus is in equinus, the talus is plantarflexed, and there is a rigid and irreducible dislocation of the talonavicular joint complex, with the navicular articulating on the dorsolateral aspect of the talar neck. It is often associated with systemic involvement.

Aims: To identify the most common anomalies accompanying to CVT (Congenital Vertical Talus). No literature investigating similar clinical data was found in the literature review.

Study design: CVT has a systemic effect and is accompanied by many anomalies. At the same time as this study, anomalies were frequently found accompanying CVT. The aim of this study is to evaluate the prenatal, natal and postnatal clinical findings associated with Congenital Vertical Talus.

Methods: Between 2012 and 2018, a total of 20 CVT patients (12 males, 8 females) were included in the study. Children between the ages of 0 and 18 who applied to the dysmorphology clinic for the study were included.

Results: Five parameters associated with CVT were detected in this study. These include intrauterine growth retardation, hypoxic birth history, hypotonia, microcephaly and cryptorchidism.

Conclusion: A detailed and multidisciplinary approach to CVT is required.
\end{abstract}

\section{Keywords}

Microcephaly, Vertical talus, Intrauterine growth retardation

\section{Introduction}

Congenital vertical talus is rare. The first clinical, anatomical, pathological and roentgenographic study of this condition was published by Henken, in 1914. A congenital vertical talus, also known as congenital convex pes valgus, is a rare foot deformity characterized by a fixed dorsal dislocation in talar head and neck na- vicular. The incidence is estimated to be one in 10,000 . Approximately half of all cases (idiopathic) are associated with deformity and 2-5 neuromuscular and genetic disorders in the remaining cases. There is evidence that some isolated deformities are transmitted as an autosomal dominant feature with incomplete penetrance [1-4]. The deformity is also known by congenital "rocker-bottom" flatfoot because of its rigid deformity with the forefoot dorsiflexed and the hindfoot plantarflexed. The term "congenital convex pes valgus" is also frequently used. To make a definite diagnosis, it is important to demonstrate that the navicular is dislocated dorsally on the neck of the talus when the foot is maintained in extreme plantar flexion $[5,6]$. Congenital vertical talus is characterized by hindfoot equinus, hindfoot valgus, forefoot abduction, and forefoot dorsiflexion at the midtarsal joint. This is usually recognized in the newborn period by the rigidity of the deformities, but it must be differentiated from the more common calcaneovalgus foot, posterior medial bowing of the tibia, and flexible flatfoot. In congenital vertical talus, the plantar surface of the foot is convex creating a rocker-bottom appearance [7].

Dysmorphology allows identification of occured before of after birth non-normative human forms that enable the identification and classification of various congenital malformations. This term provides an comparable description that all body characteristics (stature, feet, hands, neck) and face (like shape of head, nose length, position of ears, thickness of vermillion, etc.) of individuals who the same age group and same ethnicity. A genetic etiology should be suspected if a child has dysmorphic vision with one of these features: (a) Congenital anomalies; (b) Growth retardation; (c) De-

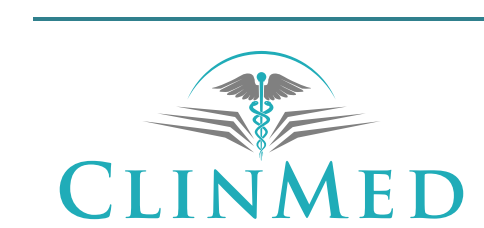

INTERNATIONAL LIBRARY

Citation: Muhsin E (2018) Common Anomalies Associated To Congenital Vertical Talus: A Single Center Experience. Int J Foot Ankle 2:013.

Accepted: August 27, 2018; Published: August 29, 2018

Copyright: (C) 2018 Muhsin E. This is an open-access article distributed under the terms of the Creative Commons Attribution License, which permits unrestricted use, distribution, and reproduction in any medium, provided the original author and source are credited. 


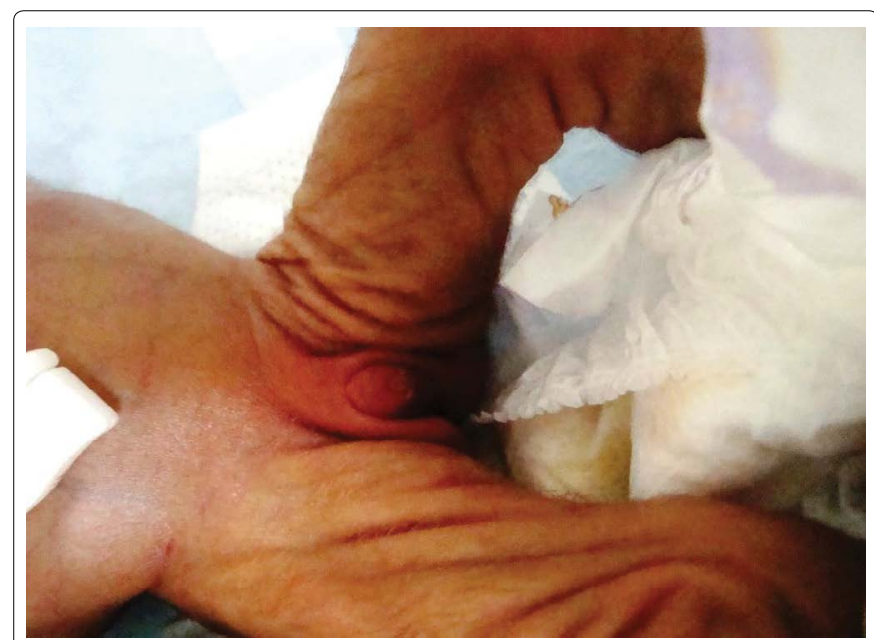

Figure 1: Trisomy 18 (Edward syndrome) children with cryptorchidism.

velopmental delay and intellectual disability or developmental regression; (d) Undeveloped seconder sexual characteristics; (e) Ambiguous genitalia [8,9].

The exact etiology of vertical talus in most cases is not known. Theories include increased intrauterine pressure and resultant tendon contractures, or an arrest in fetal development occurring between the $7^{\text {th }}$ and $12^{\text {th }}$ week of gestation [7].

Genetic abnormalities associated with vertical talus include aneuploidy of chromosome 13,15 and 18. A variety of syndromes have also been described in which vertical talus is a clinical manifestation. De Barsy syndrome is a rare genetic syndrome characterized by severe cutis laxa, joint hypermobility, growth retardation, mental retardation, and characteristic facies; orthopaedic manifestations include hip dislocation, scoliosis, and congenital vertical talus [7].

Intrauterine growth restriction (IUGR) a risk for growth retardation. Stems from the fact that the fetus does not catch the growth potential determined due to anatomical and/or functional disorders $[10,11]$.

The head circumference provides rough information about the intracranial volume. Head circumference measurement is an indirect and simple calculation method used to determine whether brain growth progresses normally. Growth around the head is very important for brain development $[12,13]$.

Hypotonia refers to an impairment that may be associated many different conditions, including those of neuromuscular, genetic, central nervous system, connective tissue, and/or metabolic origins [14]. Clinically, muscle tone is assessed by evaluating resistance to passive stretching, while hypotonia is defined as a reduction in muscle tonus. Muscle contraction and muscle, tendon and soft tissue stiffness are thought to contribute to muscle tone. The pathology of the voltage reflex mechanism and the reduction in the excitability of the segmental motor neuron pool have been suggested as the physiological basis for hypotonia [14].
Cryptorchidism is the absence of at least one testis in the scrotum (Figure 1). The incidence of cryptorchidism is high and almost $3 \%$ of boys in the western countries are operated on for this condition. Abnormalities in the hypothalamo-pituitary-testicular axis may result in cryptorchidism, and cryptorchidism is nearly almost present in individuals with a testis and abnormal sexual differentiation [15].

The presence of a hypoxic birth story in the postnatal period was investigated. For this purpose, the birth APGAR score of the patients was investigated. At the same time, these patients were followed for a long time in medical genetic clinic. Especially whether hypotonin was present or not. The times of motor development, language development and social development stages were investigated.

The APGAR score used for fetal well-being is another parameter we questioned. This score includes color, heart rate, reflexes, muscle tone and respiration. There are 3 categories according to the results of the APGAR score; low (0-3); intermediate (4-6) and normal (7-10). Low Apgar scores at birth are consistently associated with increased risk of neurological disease, such as cerebral palsy, epilepsy and cognitive impairment $[16,17]$.

\section{Materials and Methods}

Between 2012 and 2018, a total of 20 CVT patients (12 males, 8 females) were included in the study.

Hospital records of the patients were reviewed in detail and the anomalies associated with CVT were identified. The records of the patients from the Prenatal period were scanned. Here, fetal characteristics were investigated in prenatal period. Fetal movements, oligohydramnios, polyhydramnios, intrauterine growth retardation. In addition, maternal complications such as hypertension, diabetes, preeclampsia were investigated.

Three parameters related to Natal turnover of the patients were investigated. Birth style, birth weight and birth time. If the cesarean birth type was preferred, the reason for this was investigated.

Collected data were analyzed by Statistical Package for Social Sciences version 18.0 (SPSS Inc., SPSS IBM, Armonk, NY, USA). Continuous data were expressed as mean \pm standard deviation (range: minimum-maximum) whereas categorical data were denoted as numbers or percentages where appropriate. Chi-square test was used for the statistical comparisons. Two-tailed $p$ values less than 0.05 were accepted to be statistically significant.

\section{Results}

In the study, the most common comorbidities were found in CVT patients. 


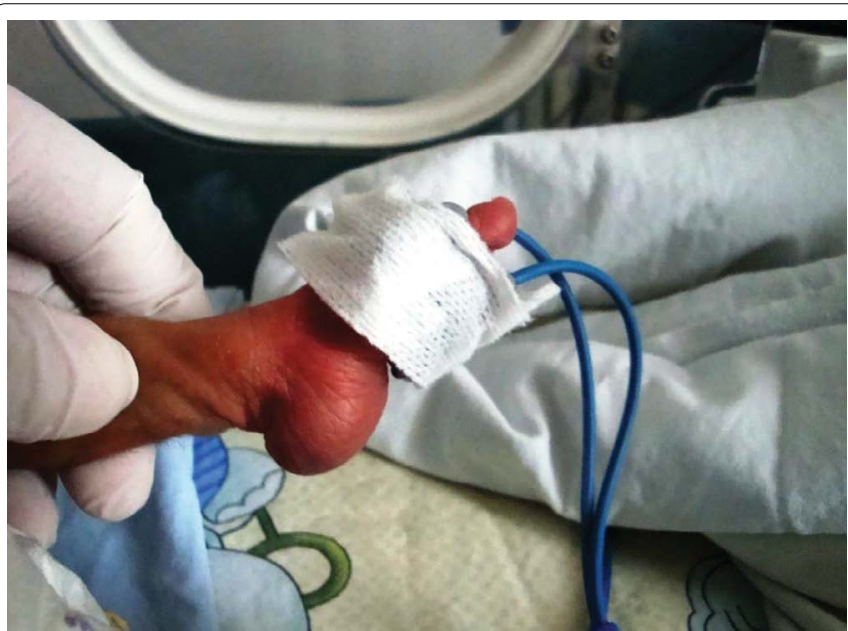

Figure 2: Trisomy 18 (Edward syndrome) children with left foot vertical talus.

IUGR (intrauterine growth retardation) was detected in 16 of 20 patients $(80 \%)$ in the prenatal period. They have received IUGR diagnosis at $20^{\text {th }}$ week during pregnancy. The average birth weight of children is $1980 \mathrm{gr}$.

In total $12 / 20$ patients, APGAR score at the $5^{\text {th }}$ minute was between 4-7 (Mild hypoxic birth trauma) The APGAR score at $4 / 12$ was found to be less than 4 . (Severe hypoxic ischemic birth trauma.) These 4 patients were followed up for a long time in neonatal intensive care unit.

The head circumference of the patients was followed for 2 years from birth. As a result, microcephaly was detected at birth in $12 / 20$ patients. The average head circumference of these patients was $33 \mathrm{~cm}$. it was found that patients who had microcephaly at birth were similarly microcephaly at 2 years age.

When the records of these patients are screened, it is the other finding that hypotonia is present in half of these findings (10/20 patients).

Cryptorchidism was detected in 8 of 12 male patients. The cryptorchidism detected was bilateral.

In addition, chromosome analysis in 20 patients revealed trisomy 18 in 6 patients (Figure 2 and Figure 3). The chromosome results of the remaining 14 patients were reported as normal.

\section{Discussion}

We haven't been found any article in the literature investigating similar clinical data. Therefore, it is difficult to compare the data of our patients with the literature.

No information was found in the literature about intrauterine growth retardation in CVT cases. In the study conducted by Romo, et al. In 2009, the incidence of IUGR in the general population was found between $3 \%$ and $7 \%[18]$. Compared to the general population and patients with CVT, the IUGR rate was much higher (80\%) at have CVT patients.

According to our results in this study, neurological

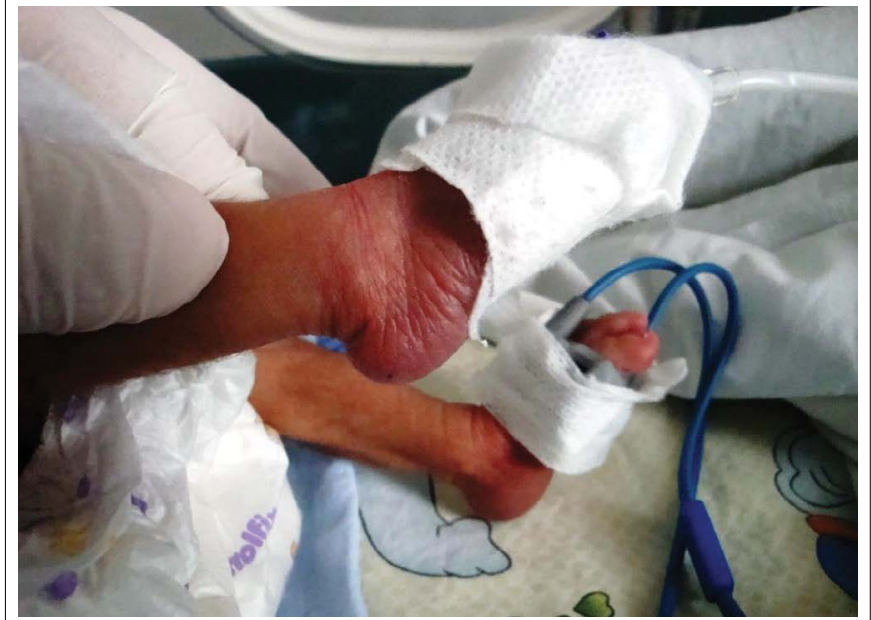

Figure 3: Trisomy 18 (Edward syndrome) children with right foot vertical talus.

anomalies in CVT patients can be divided into 2 major categories. These are: central nervous system diseases and neuromuscular diseases (the frequency of both was found equal).

There are very few publications in the literature reporting relation cryptorchidism with CVT. Vertical Talus and cryptorchidism are common in multiple pterygium syndrome cases $[19,20]$.

In a study by Merrill and colleagues, $36 \%$ of patients with CVT had neuromuscular disease (Such as Cerebral palsy, Myelomeningocel, Caudal regression syndrome, Hydrocephalus) [21]. Fetal brain abnormalities are the most common finding associated with congenital vertical talus, occurring in $63 \%$ of our cases. Abnormal conditions were usually severe and included microcephaly, migration anomalies, cerebrum, cerebellum and cerebellum underdevelopment in addition to myelomeningocele-associated Chiari II malformation. While useful in assessing USG at head growth, MRI has found an important help in identifying brain abnormalities, particularly migration and sulcation anomalies [22].

$46 \%$ of patients at this study have spinal abnormalities such as scoliosis, myelomeningocele, and tethered cord. Although spinal column malformations can be easily seen by the USG, cord and conus position are better evaluated with MRI [22].

It was associated with CVT and trisomy 13, 15 and 18. $25 \%$ of the patients in the study of Rubio, et al. had chromosomal abnormalities that is trisomy 18 (most common chromosomal anomaly in this study.). This is in keeping with prior studies describing an association of rocker bottom foot and aneuploidy of trisomy 13, 15 and $18[7,22]$. In our study, the chromosomal anomalies were the trisomy 18 that we detected at the most common. We found trisomy 18 in 6 of 20 patients in total (30\%).

\section{Conclusion}

In this study, 5 parameters were found to be fre- 
quently associated with CVT cases. These parameters; intrauterine growth retardation, hypoxic birth history, hypotonia, microcephaly and cryptorchidism. Vertical talus is a multi-systemic disease and multidisciplinary approach is needed. Vertical talus cases should be investigated in detail for prenatal, natal and postnatal period findings.

\section{References}

1. Ogata K, Schoenecker PL, Sheridan J (1979) Congenital vertical talus and its familial occurrence: An analysis of 36 patients. Clin Orthop Relat Res 128-132.

2. Hack M, Breslau N, Weissman B, Aram D, Klein N, et al. (1991) Effect of very low birth weight and subnormal head size on cognitive abilities at school age. N Engl J Med 325: 231-237.

3. Lloyd Roberts GC, Spence AJ (1958) Congenital vertical talus. J Bone Joint Surg Br 40: 33-41.

4. Dobbs MB, Purcell DB, Nunley R, Morcuende JA (2006) Early results of a new method of treatment for idiopathic congenital vertical talus. J Bone Joint Surg Am 88: 1192-1200.

5. Coleman SS, Stelling III FH, Jarrett J (1970) Pathomechanics and treatment of congenital vertical talus. Clin Orthop Relat Res 70: 62-72.

6. Hamanishi C (1984) Congenital vertical talus: Classification with 69 cases and new measurement system. J Pediatr Orthop 4: 318-326.

7. Alaee F, Boehm S, Dobbs MB (2007) A new approach to the treatment of congenital vertical talus. J Child Orthop 1 : 165-174.

8. Hunter AGW (2002) Medical genetics: 2 The diagnostic approach to the child with dysmorphic signs. CMAJ 167 367-372.

9. Featherstone K, Latimer J, Atkinson P, Pilz DT, Clarke A (2005) Dysmorphology and the spectacle of the clinic. Sociol Heal IIIn 27: 551-574.

10. Wallenstein MB, Harper LM, Odibo AO, Roehl KA, Longman RE, et al. (2012 Fetal congenital heart disease and intrauterine growth restriction: A retrospective cohort study. J Matern Neonatal Med 25: 662-665.
11. Salam RA, Das JK, Bhutta ZA (2014) Impact of intrauterine growth restriction on long-term health. Curr Opin Clin Nutr Metab Care 17: 249-254.

12. GravesAB, Mortimer JA, Larson EB, Wenzlow A, Bowen JD, et al. (1996) Head circumference as a measure of cognitive reserve. Association with severity of impairment in Alzheimer's disease. Br J Psychiatry 169: 86-92.

13. Sacco R, Militerni R, Frolli A, Bravaccio C, Gritti A, et al. (2007) Clinical, morphological, and biochemical correlates of head circumference in autism. Biol Psychiatry 62: 10381047.

14. American Physical Therapy Association. Section on Pediatrics. Pediatric physical therapy : The official journal of the Section on Pediatrics of the American Physical Therapy Association. Lippincott Williams \& Wilkins.

15. Cortes D (1998) Cryptorchidism--aspects of pathogenesis, histology and treatment. Scand J Urol Nephrol Suppl 196: 1-54.

16. Tweed EJ, Mackay DF, Nelson SM, Cooper SA, Pell JP (2016) Five-minute Apgar score and educational outcomes: Retrospective cohort study of 751,369 children. Arch Dis Child Fetal Neonatal Ed 101: 121-126.

17. (2006) The Apgar Score. Adv Neonatal Care 6: 220-223.

18. Romo A, Carceller R, Tobajas J (2009) Intrauterine growth retardation (IUGR): Epidemiology and etiology. Pediatr Endocrinol Rev 3: 332-336.

19. Konya MN, Elmas M, Özdemir Ç (2017) Analysis of musculoskeletal dysmorphic abnormalities of 20 fetuses. Eklem Hastalik Cerrahisi 28: 114-120.

20. Chen $\mathrm{H}$, Chang $\mathrm{CH}$, Misra RP, Peters HA, Grijalva NS, et al. (1980) Multiple pterygium syndrome. Am J Med Genet 7: $91-102$.

21. Merrill LJ, Gurnett CA, Connolly AM, Pestronk A, Dobbs MB (2011) Skeletal muscle abnormalities and genetic factors related to vertical talus. Clin Orthop Relat Res 469: 11671174.

22. Rubio El, Mehta N, Blask AR, Bulas DI (2017) Prenatal congenital vertical talus (rocker bottom foot): A marker for multisystem anomalies. Pediatr Radiol 47: 1793-1799. 